\title{
Linking individual-tree and whole-stand models for forest growth and yield prediction
}

Quang V Cao

\begin{abstract}
Background: Different types of growth and yield models provide essential information for making informed decisions on how to manage forests. Whole-stand models often provide well-behaved outputs at the stand level, but lack information on stand structures. Detailed information from individual-tree models and size-class models typically suffers from accumulation of errors. The disaggregation method, in assuming that predictions from a whole-stand model are reliable, partitions these outputs to individual trees. On the other hand, the combination method seeks to improve stand-level predictions from both whole-stand and individual-tree models by combining them.
\end{abstract}

Methods: Data from 100 plots randomly selected from the Southwide Seed Source Study of loblolly pine (Pinus taeda $\mathrm{L}$.) were used to evaluate the unadjusted individual-tree model against the disaggregation and combination methods.

Results: Compared to the whole-stand model, the combination method did not show improvements in predicting stand attributes in this study. The combination method also did not perform as well as the disaggregation method in tree-level predictions. The disaggregation method provided the best predictions of tree- and stand-level survival and growth.

Conclusions: The disaggregation approach provides a link between individual-tree models and whole-stand models, and should be considered as a better alternative to the unadjusted tree model.

Keywords: Disaggregation; Combination method; Loblolly pine; Pinus taeda

\section{Background}

Information provided by growth and yield models is essential for forest managers to make informed decisions on how to manage their forests. Munro (1974) classified growth and yield models into whole-stand models and individual tree models. He further separated individual-tree models into distance-independent and distance-dependent models. The whole-stand models (low resolution) and individual-tree models (high resolution) represent two extremes. In the middle are medium-resolution models such as diameter-distribution models and stand-table projection models, which provide information for each diameter class (Figure 1).

Each type of model has its own benefits and drawbacks. Whole-stand models often provide well-behaved

Correspondence: qcao@lsu.edu

School of Renewable Natural Resources, Louisiana State University Agricultural Center, Baton Rouge, LA 70803, USA outputs at the stand level, but these outputs lack information on stand structures. Detailed information from individual-tree models and size-class models, on the other hand, typically results in stand-level outputs that are not as accurate or precise because they suffer from accumulation of errors (Garcia 2001, Qin and Cao 2006).

Daniels and Burkhart (1988) attempted to link different types of growth and yield models by developing a framework for an integrated system in which models of different resolutions are related in a unified mathematical structure. The functions used in these models can therefore be considered invariant at different levels of dimensionality.

Zhang et al. (1997) used the multi-response parameter estimation developed by Bates and Watts $(1987,1988)$ to constrain an individual-tree model by optimizing for both tree and diameter-class levels. This approach was later modified by Cao (2006) to produce a constrained 


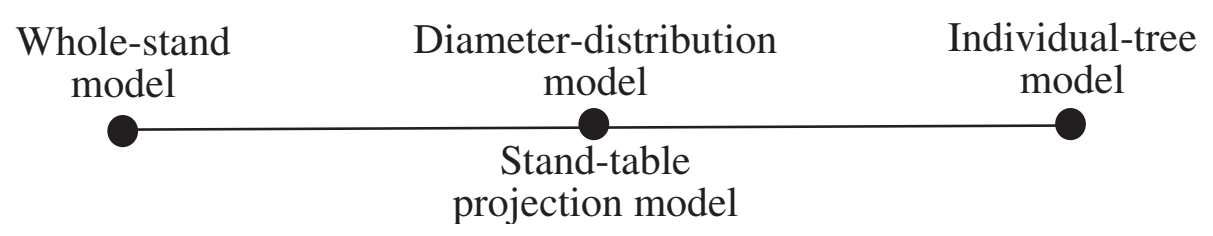

$\begin{array}{lc}\stackrel{\text { low }}{\text { high }} \\ \text { resolution } & \text { resolution }\end{array}$

Figure 1 Relative position of different types of growth and yield models in terms of the resolutions of the outputs.

tree model that was optimized for both tree and stand levels.

Disaggregation method is a method that has been used by many researchers for linking an individual-tree model and a whole-stand model (Ritchie and Hann 1997). In this method, outputs from the individual-tree model are adjusted such that the resulting stand summary matches prediction from a whole-stand model.

The disaggregation method above assumes that outputs from whole-stand models are more reliable than those from individual-tree models. Yue et al. (2008) found that stand-level outputs from whole-stand and individual-tree models could be combined to improve predictions. The weighted average approach was extended by Zhang et al. (2010) to include stand-level outputs from a diameter distribution model.

In this paper, the disaggregation method and combination method were evaluated against the unadjusted individual-tree model by use of data from unthinned loblolly pine (Pinus taeda L.) plantations.

\section{Review of methods for linking individual-tree models and whole-stand models}

Stand-level summary is obtained by aggregating (or summing) tree-level outputs from individual-tree models. Because this summary is often believed to be not as accurate and precise as direct prediction from a whole-stand model, the individual-tree model can be adjusted such that the resulting stand-level output matches that from a whole-stand model. In other words, output from the whole-stand model is disaggregated to tree level by use of some disaggregating function.

Ritchie and Hann (1997) provided an excellent review on disaggregation methods, classifying the disaggregating functions into additive and proportional. In the additive growth method, the basal area growth of each tree is equal to the average tree basal area growth plus an adjustment based on tree basal area (Harrison and
Daniels 1988) or tree diameter (Dhote 1994). Another category of disaggregation methods involves proportional allocations that can be applied to either growth or yield. In the proportional yield method, predicted tree basal area is adjusted to match predicted stand basal area (Clutter and Allison 1974, Clutter and Jones 1980, Pienaar and Harrison 1988, Nepal and Somers 1992, McTague and Stansfield 1994, 1995). The proportional growth method involves adjusting predicted tree basal area growth to match predicted stand basal area growth (Campbell et al. 1979, Moore et al. 1994), tree volume growth to match stand volume growth (Dahms 1983, Zhang et al. 1993), or tree diameter growth to match stand diameter growth (Leary et al. 1979).

Qin and Cao (2006) evaluated four methods to link an individual-tree model and a whole-stand model by use of disaggregation. In the proportional yield method, the predicted tree survival probability, diameter, and total height were multiplied by adjustment factors (equations $1-3$ of Table 1). Tree diameter and height growth were adjusted in the proportional growth method, while tree survival probability was adjusted based on the ratio of dead and alive probabilities (equations 4-6 of Table 1). The constrained least squares method (Matney et al. 1990, Cao and Baldwin 1999) was used to adjust tree attributes (tree survival probability, squared diameter, or total height) by minimizing the sums of squared differences between the predicted and adjusted attributes, subject to the constraints that the aggregations had to match predictions from a whole-stand model (equations 7-8 of Table 1). Finally, in the coefficient adjustment method, adjusting coefficients were added to modify the coefficients of the original individual-tree model to yield stand attributes identical to those produced by the whole-stand model (equations 10-12 of Table 1). The four methods evaluated produced similar results, with the coefficient adjustment selected as the method to disaggregate predicted stand growth among trees in the tree list. The adjusted tree model combined the 


$$
\begin{aligned}
& 1 \quad \tilde{p}_{2, i}=\hat{p}_{2 i}\left(\frac{s \hat{N}_{2}}{\sum \hat{p}_{2 j}}\right) \\
& 2 \quad \tilde{d}_{2 i}^{2}=\hat{d}_{2 i}^{2}\left(\frac{s \hat{B}_{2} / K}{\sum \hat{p}_{2 j} \hat{d}_{2 j}^{2}}\right)
\end{aligned}
$$$$
3 \quad \tilde{h}_{2 i}=\hat{h}_{2 i}\left(\frac{s\left(\hat{V}_{2}-a \hat{N}_{2}\right)}{b \sum_{j} \hat{p}_{2 j} \hat{d}_{2 j} \hat{h}_{2 j}}\right)
$$

Proportional growth

Constrained least squares

Coefficient adjustment

Disaggregation

Cao (2006)

$$
\begin{aligned}
& 5 \quad \tilde{d}_{2 i}^{2}=d_{1 i}^{2}+\left(\frac{s \hat{B}_{2} / K-\sum \tilde{p}_{2 j} d_{1 j}^{2}}{\sum \tilde{p}_{2 j}\left(\hat{d}_{2 j}^{2}-d_{1 j}^{2}\right)}\right)\left(\hat{d}_{2 i}^{2}-d_{1 i}^{2}\right) \\
& 6 \quad \tilde{h}_{2 i}=h_{1 i}+\left(\frac{s\left(\hat{V}_{2}-a \hat{N}_{2}\right)-b \sum \tilde{\rho}_{2 j} \tilde{d}_{2 j} h_{1 j}}{b \sum \tilde{p}_{2 j} \tilde{d}_{2 j}^{2}\left(\hat{h}_{2 j}-h_{1 i}\right)}\right)\left(\hat{h}_{2 i}-h_{1 i}\right)
\end{aligned}
$$$$
7 \quad \tilde{p}_{2 i}=\left(\hat{p}_{2 i}+s \hat{N}_{2}-\sum \hat{p}_{2 j}\right) / n
$$

$$
\tilde{d}_{2 i}^{2}=\hat{d}_{2 j}^{2}-\tilde{p}_{2 i}\left(\frac{\sum \tilde{p}_{2 j} \hat{d}_{2 j}^{2}-s \hat{B}_{2} / K}{\sum_{j j} \tilde{p}_{2 j}^{2}}\right)
$$$$
\tilde{h}_{2 i}=\hat{h}_{2 i}-\tilde{p}_{2 i} \tilde{d}_{2 i}^{2}\left(\frac{\sum \tilde{p}_{2 j} \tilde{j}_{2 j} \hat{h}_{2 j}+s\left(a \hat{N}_{2}-\hat{V}_{2}\right) / b}{\sum \tilde{p}_{2 j} \tilde{d}_{2 j}^{4}}\right)
$$

10

$$
\tilde{p}_{2 i}=p_{1 i} /\left(1+\exp \left[a_{0}+a_{1} H_{1}+a_{2} m_{p}\left(d_{1 i} / D q_{1}\right)\right]\right)
$$

Constraining individual-tree model with diameter-class attributes

Constraining individual-tree model with stand attributes

$$
\begin{aligned}
& \tilde{d}_{2 i}=d_{1 i}\left\{1+\exp \left[\beta_{0}+\beta_{1} \ln B_{1}+\beta_{2} A_{1}+\beta_{3} \ln H_{1}+\beta_{4} m_{d}\left(\frac{d_{i 1}}{D Q_{1}}\right)+\beta_{5} \ln h_{11}\right]\right\} \\
& \tilde{h}_{2 i}=h_{11}\left\{1+\exp \left[\gamma_{0}+\gamma_{1} \ln B_{1}+\gamma_{2} A_{1}+\gamma_{3} \ln H_{1}+\gamma_{4} m_{h}\left(\frac{d_{11}}{D D_{4}}\right)+\gamma_{5}\left(\frac{h_{u}}{H_{1}}\right)+\gamma_{6} \ln d_{11}\right]\right\}
\end{aligned}
$$

$$
\tilde{p}_{2 i}=\hat{p}_{2 i}^{m_{p}}
$$

$$
\tilde{d}_{2 i}^{2}=d_{1 i}^{2}+\left(\frac{s \hat{B}_{2} / K-\sum \tilde{p}_{2 j} d_{1 j}^{2}}{\sum \tilde{p}_{2 j}\left(\hat{d}_{2 j}^{2}-d_{1 j}^{2}\right)}\right)\left(\hat{d}_{2 i}^{2}-d_{1 i}^{2}\right)
$$

15 $\left\{\begin{array}{l}\hat{p}_{2 i}=1 /\left(1+\exp \left[a_{0}+a_{1} N_{1}+a_{2} B_{1}+a_{3} d_{1 i}\right]\right) \\ \hat{n}_{2, k}=\sum_{i=1}^{n_{1, k}} \hat{p}_{2 i}\end{array}\right.$

16

$$
\left\{\begin{array}{l}
\hat{d}_{2 i}=d_{1 i}+\beta_{1}\left(\frac{A_{2}}{A_{1}}\right)^{\beta_{2}} H_{1}^{\beta_{3}} B_{1}^{\beta_{4}} d_{1}^{\beta_{5}} \\
\hat{b}_{2, k}=K \sum_{i=1}^{n_{1,1}} \hat{p}_{2 i} \hat{d}_{2 i}^{2}
\end{array}\right.
$$

17

18 


\section{Table 1 List of adjustment functions used in recent methods to link models of different resolutions (Continued)}

\begin{tabular}{|c|c|c|c|}
\hline Yue et al. (2008) & Combined estimator & 19 & $\begin{array}{l}\tilde{B}_{2}=w \hat{B}_{2 T}+(1-w) \hat{B}_{2 S} \\
\text { where } w \text { is selected to minimize the variance of } \tilde{B}_{2} \text {. }\end{array}$ \\
\hline Zhang et al. (2010) & Combined estimator & 20 & $\begin{array}{l}\tilde{B}_{2}=w_{1} \hat{B}_{2 T}+w_{2} \hat{B}_{2 S}+w_{3} \hat{B}_{2 D} \\
\text { where } w_{k} \text { is selected to minimize } \sum\left(B_{2}-\tilde{B}_{2}\right)^{2} \text {, and } \sum_{k}^{3} w_{k}=1 .\end{array}$ \\
\hline Cao (2010) & 1 & 21 & $\tilde{p}_{2 i}=\hat{p}_{2 i}^{m}$ \\
\hline Tree survival & 2 & 22 & $\tilde{p}_{2 i}=\frac{\hat{p}_{2 i}}{\hat{p}_{2 i}+m_{p}\left(1-\hat{p}_{2 i}\right)}$ \\
\hline & 3 & 23 & $\tilde{p}_{2 i}=1 /\left(1+\exp \left[m_{p} a_{0}+a_{3} d_{1 i}\right]\right)$ \\
\hline & 4 & 24 & $\tilde{p}_{2 i}=1 /\left(1+\exp \left[a_{0}+a_{1} N_{1}+a_{2} B_{1}+m_{p} d_{1 i}\right]\right)$ \\
\hline & 5 & 25 & $\tilde{p}_{2 i}=\hat{p}_{2 i}+\left(\frac{s \hat{N}_{2}-\sum_{j} \hat{p}_{2 j}}{\sum \hat{p}_{2}}\right)\left(1-\hat{p}_{2 i}\right)$ \\
\hline Cao (2010) & 1 & 26 & $\begin{aligned}\left(s N_{1}-\sum_{j} p_{2 j}\right) \\
\hat{d}_{2 i}=d_{1 i}+m_{d} d_{1}^{\beta_{5}}\end{aligned}$ \\
\hline Tree diameter growth & 2 & 27 & $\hat{d}_{2 i}=d_{1 i}+\beta_{1}\left(\frac{A_{2}}{A_{1}}\right)^{\beta_{2}} H_{1}^{\beta_{3}} B_{1}^{\beta_{4}} d_{1}^{m_{d}}$ \\
\hline & 3 & 28 & $\tilde{d}_{2 i}^{2}=d_{1 i}^{2}+\left(\frac{s \hat{B}_{2} / k-\sum_{j} \tilde{p}_{2 j} d_{1 j}^{2}}{\sum_{j} \tilde{p}_{2 j}\left(\hat{d}_{2 j}^{2}-d_{1 j}^{2}\right)}\right)\left(\hat{d}_{2 i}^{2}-d_{1 i}^{2}\right)$ \\
\hline
\end{tabular}

\footnotetext{
1/ Notation:
}

$A_{1}=$ stand age at the beginning of the growth period.

$A_{2}=$ stand age at the end of the growth period.

$H_{1}=$ dominant height at age $A_{1}$.

$N_{1}=$ number of trees per ha at age $A_{1}$.

$\hat{N}_{2}=$ predicted number of trees per ha at age $A_{2}$.

$B_{1}=$ stand basal area at age $A_{1}$.

$\hat{B}_{2}=$ predicted stand basal area at age $A_{2}$.

$\hat{B}_{2 D}=$ predicted stand basal area at age $A_{2}$ from a diameter distribution model.

$\hat{B}_{2 S}=$ predicted stand basal area at age $A_{2}$ from a whole-stand model.

$\hat{B}_{2 T}=$ predicted stand basal area at age $A_{2}$ from an individual-tree model.

$\tilde{B}_{2}=$ combined estimator for stand basal area at age $A_{2}$.

$\hat{V}_{2}=$ predicted volume per ha at age $A_{2}, D q_{1}=$ quadratic mean diameter at age $A_{1}$.

$a$ and $b=$ parameters of the individual tree volume equation, $v_{i}=a+b d_{i}^{2} h_{i}$.

$v_{i}, d_{i}$, and $h_{i}=$ tree volume, $\mathrm{dbh}$, and total height of tree $i$, respectively.

$s=$ plot size in ha.

$K=\pi / 40000=$ constant to convert diameter in $\mathrm{cm}$ to area in $\mathrm{m}_{2}$.

$n=$ number of trees in the plot.

$d_{1 i}$ or $d_{1 j}=\mathrm{dbh}$ of tree $i$ or $j$ at age $A_{1}$

$\hat{d}_{2 i}$ or $\hat{d}_{2 j}=$ predicted dbh of tree $i$ or $j$ at the end of the growth period.

$\tilde{d}_{2 i}=$ adjusted dbh of tree $i$ at the end of the growth period.

$h_{1 i}=$ total height of tree $i$ at age $A_{1}$.

$\hat{h}_{2 i}$ or $\hat{h}_{2 j}=$ predicted total height of tree $i$ or $j$ at the end of the growth period.

$\tilde{h}_{2 i}=$ adjusted total height of tree $i$ at the end of the growth period.

$p_{1 i}=$ survival probability of tree $i$ at age $A_{1}$.

$\hat{p}_{2 i}$ or $\hat{p}_{2 j}=$ predicted survival probability of tree $i$ or $j$ at the end of the growth period.

$\tilde{p}_{2 i}$ or $\tilde{p}_{2 j}=$ adjusted survival probability of tree $i$ or $j$ at the end of the growth period.

$a_{0} \ldots a_{3}=$ parameters of the tree survival equation.

$\beta_{0} \ldots \beta_{5}=$ parameters of the tree diameter growth equation

$\gamma_{0} \ldots \gamma_{6}=$ parameters of the tree height growth equation.

$n_{1, k}=$ number of trees of the $k^{\text {th }}$ diameter class at age $A_{1}$.

$\hat{n}_{2, k}=$ predicted number of trees of the $k^{\text {th }}$ diameter class at age $A_{2}$.

$\hat{b}_{2, k}=$ predicted basal area of the $k^{\text {th }}$ diameter class at age $A_{2}$, and $m_{p}, m_{d}$, and $m_{h}=$ adjustment coefficients to be iteratively solved to ensure that the resulting

number of trees per ha, stand basal area, and stand volume, respectively, match those produced by the whole-stand model.

best features of whole-stand and individual-tree models. Compared to the unadjusted tree model, the adjusted model performed better in predicting stand attributes in terms of stand density, basal area, and volume, especially for long projection periods. The adjusted model also provided comparable predictions of tree diameter, height, and survival probability.

Cao (2006) evaluated a disaggregation method against two approaches to constrain an individual-tree model. In the disaggregation method, the predicted tree survival 
probability was adjusted with a simple power function, in which the power was iteratively solved such that the adjusted survival probability summed up to the predicted stand density (equation 13 of Table 1). The proportional growth formula was used in adjusting diameter growth (equation 14 of Table 1). The individual-tree model was constrained by diameter-class attributes (equations 15-16 of Table 1) by use of the multiresponse parameter estimation method (Zhang et al. 1997, Bates and Watts 1987, 1988). Also included in the evaluation was a similar approach to constrain the individual-tree model by stand attributes (equations 17-18 of Table 1). Cao (2006) found that while the two constrained models performed slightly better than the unconstrained tree model in predicting tree and stand attributes, the disaggregation method provided the best predictions of tree- and stand-level survival and growth.

Cao (2010) listed different disaggregation methods for predicting tree survival and diameter growth. These include five disaggregation methods for adjusting tree survival probability (equations $21-25$ of Table 1 ) and three methods for diameter growth adjustment (equations 26-28 of Table 1). His results showed that the different methods produced similar results. Cao (2010) also found that use of observed rather than predicted stand attributes for disaggregation led to improved predictions for tree survival and diameter growth, i.e. the quality of the tree-level predictions in disaggregation depended on the reliability of the stand predictions.

Yue et al. (2008) used the method introduced by Bates and Granger (1969) and Newbold and Granger (1974) to combine stand-level outputs from whole-stand and individual-tree models. The combined estimator is a weighted average of outputs from both models (equation 19 of Table 1). The optimum weights were selected to minimize the the variance of the combined estimator. Zhang et al. (2010) extended this approach to also include stand-level outputs from a diameter distribution model (equation 20 of Table 1). The least-squares estimate of the weights was computed according to Tang (1992, 1994).

\section{Methods}

Stand- and tree-level growth models developed by Cao (2006) were used in this study. The whole-stand model consisted of equations for predicting stand density in terms of number of trees and basal area per hectare as follows:

$$
\begin{aligned}
\hat{N}_{2, i}= & N_{1, i} /\left[1+\exp \left(16.3197-42.4204 R S_{1, i}-0.7466 H_{1, i}\right.\right. \\
& \left.\left.-0.0269 N_{1, i} / A_{1}+50.2622 / A_{1}\right)\right],
\end{aligned}
$$

$$
\hat{B}_{2, i}=B_{1, i} /\left[1+\exp \left(-3.3259-0.7800 B_{1, i} / A_{1}+41.0393 / A_{1}\right)\right]
$$

where:

$N_{1, i}=$ number of trees per ha in plot $i$ at age $A_{1}$,

$\hat{N}_{2, i}=$ predicted number of trees per ha in plot $i$ at age $A_{2}$,

$H_{1, i}=$ average dominant and codominant height (m) of plot $i$ at age $A_{1}$,

$R S_{1, i}=\left(10,000 / N_{1, i}\right)^{0.5} / H_{1, i}=$ relative spacing of plot $i$ at age $A_{1}$,

$B_{1, i}=$ stand basal area $\left(\mathrm{m}^{2} / \mathrm{ha}\right)$ of plot $i$ at age $A_{1}$, and

$\hat{B}_{2, i}=$ predicted stand basal area $\left(\mathrm{m}^{2} / \mathrm{ha}\right)$ of plot $i$ at age $A_{2}$.

The individual-tree model included equations for predicting tree survival probability and diameter growth as follows:

$$
\begin{array}{r}
\hat{p}_{i j}=\left[1+\exp \left(1.3586-0.0010 N_{1, i}+0.1042 B_{1, i}-0.2902 d_{1, i j}\right)\right]^{-1} \\
\hat{d}_{2, i j}=d_{1, i j}+0.7168\left(\frac{A_{2}}{A_{1}}\right)^{2.0192} H_{1, i}{ }^{-1.0111} B_{1, i}{ }^{-0.3166} d_{1, i j}{ }^{1.5117}
\end{array}
$$

where:

$\hat{p}_{i j}=$ predicted probability that tree $j$ in plot $i$ is alive at age $A_{2}$, given that it was alive at age $A_{1}$, $d_{1, i j}=$ diameters $(\mathrm{cm})$ of tree $j$ in plot $i$ at age $A_{1}$, and

$\hat{d}_{2, i j}=$ predicted diameters $(\mathrm{cm})$ of tree $j$ in plot $i$ at age $A_{2}$.

\section{Data}

Equations (1, 2, 3 and 4) above were derived from 100 plots from loblolly pine (Pinus taeda L.) plantations in the Southwide Seed Source Study, which include 15 seed sources planted at 13 locations across 10 southern states (Wells and Wakeley 1966).

Data used in this study were from another 100 plots, also randomly selected from the Southwide Seed Source Study. Each 0.0164 ha plot consisted of 49 trees, planted at a $1.8 \mathrm{~m} \times 1.8 \mathrm{~m}$ spacing. Tree diameters and survival were recorded at ages $10,15,20$, and 25 years, resulting in a total of 300 growth periods (Table 2).

\section{Methods evaluated}

In addition to the individual-tree model (equations 3 and 4), the disaggregation and combination methods were evaluated in this study.

\section{Disaggregation method}

The tree survival probability $\left(\hat{p_{i j}}\right)$ predicted from equation (3) was adjusted by use of Cao's (2010) method as follows: 
Table 2 Means (and standard deviations) of stand and tree attributes, by age

\begin{tabular}{lllll}
\hline Attribute & \multicolumn{4}{l}{ Stand age (years) } \\
\cline { 2 - 5 } & $\mathbf{1 0}$ & $\mathbf{1 5}$ & $\mathbf{2 0}$ & $\mathbf{2 5}$ \\
\hline Dominant height $(\mathrm{m})$ & $9.1(1.3)$ & $13.4(1.6)$ & $16.9(1.9)$ & $19.9(2.2)$ \\
Number of trees/ha & $1696(627)$ & $1448(548)$ & $1143(350)$ & $1013(334)$ \\
Basal area $\left(\mathrm{m}^{2} / \mathrm{ha}\right)$ & $19.2(5.6)$ & $28.8(5.9)$ & $33.2(8.1)$ & $37.4(9.4)$ \\
Tree diameter $(\mathrm{cm})$ & $11.6(3.1)$ & $15.4(4.1)$ & $18.7(4.6)$ & $21.0(5.2)$ \\
\hline
\end{tabular}

$$
\tilde{p}_{i j}=\hat{p}_{i j}{ }^{a}
$$

where $\alpha$ is the adjustment coefficient used to match the sum of adjusted tree survival probabilities $\left(\tilde{p}_{i j}\right)$ to predictions from the stand survival model (equation 1 ).

From equation (4), the projected tree diameter $\left(\hat{d}_{2, i j}\right)$ was adjusted (Cao 2010) so that the resulting stand basal area matches the prediction from the whole-stand model (equation 2):

$$
\tilde{d}_{2, i j}^{2}=d_{1, i j}^{2}+\beta\left(\hat{d}_{2, i j}^{2}-d_{1, i j}^{2}\right)
$$

where:

$$
\begin{aligned}
& \beta=\frac{s \widehat{B}_{2, i} / K-\sum \tilde{p}_{i j} d_{1, i j}^{2}}{\sum_{K=\pi / 40}\left[\tilde{p}_{i j}\left(\hat{d}_{2, i j}^{2}-d_{1, i j}^{2}\right)\right]} \text {, and: } \\
& K=00 .
\end{aligned}
$$

\section{Combination method}

The combined estimator of stand survival was the weighted average of stand-level predictions from the whole-stand model (equation 1) and the individual-tree model (equation 3). The weights were computed according to a method described by Tang $(1992,1994)$ and applied by Zhang et al. (2010). A similar procedure was applied to compute the combined estimator for stand basal area.

Predictions from the individual-tree model were then adjusted from the combined estimators for stand survival and basal area, using the disaggregation method described earlier.

\section{Evaluation criteria}

The performance of the unadjusted, disaggregation, and combination methods was evaluated at both stand and tree levels, based on the following statistics.

Mean difference:

$$
\mathrm{MD}=\sum\left(y_{i}-\hat{y}_{i}\right) / n
$$

Mean absolute difference:

$$
\mathrm{MAD}=\sum\left|y_{i}-\hat{y}_{i}\right| / n
$$

Fit index:

$$
\mathrm{FI}=\sum\left(y_{i}-\hat{y}_{i}\right)^{2} /\left(y_{i}-\bar{y}\right)^{2}
$$

Log-likelihood:

$$
-2 \ln (L)=-2\left[\sum p_{i} \ln \left(p_{i}\right)+\sum\left(1-p_{i}\right) \ln \left(1-p_{i}\right)\right]
$$

where:

$y_{i}$ and $\hat{y}_{i}=$ observed and predicted values at the end of the growth period of stand variables (stand survival and basal area) or tree variables (tree diameter and survival probability),

$$
\begin{aligned}
& \bar{y}=\text { average of } y_{i}, \\
& n=\text { number of observations, and } \\
& p_{i}=\text { predicted survival probability of tree } i .
\end{aligned}
$$

\section{Results and discussion}

Table 3 shows that the whole-stand model (disaggregation method) produced the best MD and MAD values for stand density while the combination method yielded the best FI value. For stand basal area, all of the best evaluation statistics came from the whole-stand model (Table 3). At tree level, the disaggregation method returned the best evaluation statistics for both tree survival probability and tree diameter (Table 3).

\section{Disaggregation method}

From Table 3, it is clear that the whole-stand model was more accurate (lower MD) and precise (lower MAD and higher FI) in predicting stand density and basal area than the individual-tree model. The differences were substantial. Compared to the individual-tree model, the whole-stand model decreased MD by 88 and $97 \%$, decreased MAD by 15 and 46\%, and increased FI by 8 and $28 \%$ for stand density and stand basal area, respectively. Predicted stand attributes from the tree-level model were not as reliable because they were obtained through summation of individual-tree predictions, resulting in accumulation of error.

Qin and Cao (2006) showed that a tree-level model, after being adjusted from observed stand attributes through disaggregation, outperformed the unadjusted tree model. They inferred that the performance of disaggregation models depended largely on how close the stand predictions were to the observed values. The whole-stand model seemed a good candidate in this case, yielding FI values of 0.825 and 0.862 in predicting stand density and basal area, respectively. The tree-level statistics support this hypothesis: the disaggregation model reduced MD by 26 and $19 \%$, and MAD by 14 and $11 \%$ for tree survival probability and tree diameter, respectively, as compared to the unadjusted tree model. It 
Table 3 Stand-level and tree-level evaluation statistics for three methods

\begin{tabular}{llll}
\hline Statistic $^{1 /}$ & $\begin{array}{l}\text { Unadjusted tree } \\
\text { model }\end{array}$ & $\begin{array}{l}\text { Disaggregation } \\
\text { method }\end{array}$ & $\begin{array}{l}\text { Combination } \\
\text { method }\end{array}$ \\
\hline
\end{tabular}

Stand level

Stand density (trees/ha)

\begin{tabular}{llll} 
MD & 28.1 & $\mathbf{- 3 . 5 ^ { 2 / }}$ & 4.1 \\
MAD & 176.1 & $\mathbf{1 4 8 . 8}$ & 149.4 \\
FI & 0.765 & 0.825 & $\mathbf{0 . 8 3 0}$ \\
\multicolumn{2}{l}{ Stand basal area $\left(\mathrm{m}^{2} / \mathrm{ha}\right)$} & & \\
MD & 2.05 & $\mathbf{0 . 0 6}$ & 1.89 \\
MAD & 3.99 & $\mathbf{2 . 1 7}$ & 3.87 \\
FI & 0.676 & $\mathbf{0 . 8 6 2}$ & 0.699
\end{tabular}

Tree level

Tree survival probability

\begin{tabular}{llll} 
MD & 0.019 & $\mathbf{- 0 . 0 1 4}$ & 0.019 \\
MAD & 0.239 & $\mathbf{0 . 2 0 6}$ & 0.239 \\
$-2 \ln (\mathrm{L})$ & 5167 & $\mathbf{4 6 1 5}$ & 4976 \\
\multicolumn{2}{l}{ Tree diameter $(\mathrm{cm})$} & & \\
$\mathrm{MD}$ & 0.16 & $\mathbf{- 0 . 1 3}$ & 0.27 \\
$\mathrm{MAD}$ & 0.94 & $\mathbf{0 . 8 4}$ & 1.03 \\
$\mathrm{FI}$ & 0.939 & $\mathbf{0 . 9 5 2}$ & 0.927 \\
\hline
\end{tabular}

"Notations:

$\mathrm{MD}=\sum\left(y_{i}-\hat{y}_{i}\right) / n ; \mathrm{MAD}=\sum\left|y_{i}-\hat{y}_{i}\right| / n ; \mathrm{Fl}=\sum\left(y_{i}-\hat{y}_{i}\right)^{2} /\left(y_{i}-\bar{y}\right)^{2} ;-2 \ln$ $(L)=-2\left[\Sigma p_{i} \ln \left(p_{i}\right)+\Sigma\left(1-p_{i}\right) \ln \left(1-p_{i}\right)\right]$, where $y_{i}$ and $\hat{y}_{i}=$ observed and predicted values at the end of the growth period of stand variables (stand survival and basal area) or tree variables (tree diameter and survival probability); $\bar{y}=$ average of $y_{i}, n=$ number of observations, and $p_{i}=$ predicted survival probability of tree $i$.

${ }^{2 /}$ For each evaluation statistic, the bold italic number denotes the best among three methods.

also decreased $-2 \ln (\mathrm{L})$ for tree survival by $11 \%$ and increase FI for tree diameter by $1 \%$.

\section{Combination method}

In this study, combining stand predictions from the whole-stand and individual-tree models resulted in predictions of stand density and basal area that were better than those from the individual-tree model, but not as good as those from the whole-stand model. Among six evaluation statistics considered, the combination method only edged the whole-stand model in fit index $(0.830$ versus 0.825 ), while came in second for the remaining statistics. This was contrary to past reports of superior performance by the combination method (Yue et al. 2008, Zhang et al. 2010). In a study by Zhang et al. (2010), similar fit index values, ranging from 0.9466 to 0.9494 , were obtained for predicted stand basal area from three different types of models for the validation data set. In this study, a considerable difference in fit index of stand basal area prediction between the individual-tree model (0.676) and the whole-stand model (0.862) might result in mediocre performance of the combination method (FI $=0.699$ for stand basal area).

The tree survival model that was disaggregated from the combined estimator gave similar evaluation statistics as did the unadjusted tree survival equation (Table 3). On the other hand, the tree diameter model from the combination method performed worse than the unadjusted tree diameter growth equation (Table 3 ).

Tree-level predictions were disaggregated from the whole-stand model for the disaggregation method and from the combined estimator for the combination method. Based on the data from this study, the disaggregation method was better for predicting both tree survival and diameter in terms of all evaluation statistics.

\section{Conclusions}

The disaggregation method involves adjusting outputs from the individual-tree model to match predictions from the whole-stand model. It was shown in previous findings and also in this study that this method provided better predictions of tree survival and diameter growth. Compared to the whole-stand model, the combination method did not show improvements in predicting stand attributes in this study. The combination method also did not perform as well as the disaggregation method in tree-level predictions.

\section{Competing interest}

The author declares that he has no competing interests.

\section{Acknowledgement}

Funding for this project was provided in part by the McIntire-Stennis funds.

Received: 25 July 2014 Accepted: 4 September 2014

Published online: 14 October 2014

\section{References}

Bates DM, Watts DG (1987) A generalized Gauss-Newton procedure for multi-response parameter estimation. SIAM J Sci Stat Comput 8:4-55

Bates DM, Watts DG (1988) Nonlinear regression analysis and its application. Wiley, New York. 365

Bates JM, Granger CWJ (1969) The combination of forecasts. Oper Res Q 20:451-468

Campbell RG, Ferguson IS, Opie JE (1979) Simulating growth and yield of mountain ash stands: a deterministic model. Aust For Res 9:189-202

Cao QV (2006) Predictions of individual-tree and whole-stand attributes for loblolly pine plantations. For Ecol Manage 236:342-347

Cao QV (2010) Adjustments of individual-tree survival and diameter growth equations to match whole-stand attributes. In: Proc of the South Silvic Res Conf USDA For Serv Gen Tech Rep SRS-121, pp 369-373

Cao QV, Baldwin VC, Jr (1999) A new algorithm for stand table projection models. Forest Sci 45:506-511

Clutter JL, Allison BJ (1974) A growth and yield model for Pinus radiata in New Zealand. In: Fries J (ed) Growth Models for Tree and Stand Simulation, Res. Note 30. Royal College of Forestry, Stockholm, pp 130-160

Clutter JL, Jones BJ, Jr (1980) Prediction of Growth after Thinning of Old-Field Slash Pine Plantations. USDA For Serv Res Pap SE-217, p 14

Dahms WG (1983) Growth-Simulation Model for Lodgepole Pine in Central Oregon. USDA For Serv Res Pap PNW-302, p 22

Daniels RF, Burkhart HE (1988) An integrated system of forest stand models. For Ecol Manage 23:159-177

Dhote JF (1994) Hypotheses about competition for light and water in even-aged common beech (Fagus silvatica L). For Ecol Manage 69:219-232 
Garcia O (2001) On bridging the gap between tree-level and stand-level models. In: Rennolls K (ed) Proceedings of IUFRO 4.11 Conference "Forest Biometry, Modelling and Information Science". University of Greenwich. 25-29 June 2001 http://cms1.gre.ac.uk/conferences/iufro/proceedings/garcia1.pdf

Harrison WC, Daniels RF (1988) A new biomathematical model for growth and yield of loblolly pine plantations. In: Ek AR, Shifley SR, Burk TE (ed) Forest Growth Modeling and Prediction, vol 1. USDA North Central Forest Experiment Station, St. Paul, MN, pp 293-304. USDA For Serv Gen Tech Rep NC-120

Leary RA, Holdaway MR, Hahn JT (1979) Diameter growth allocation rule. In: A generalized forest growth projection system applied to the Lake States region. USDA For Serv Gen Tech Rep NC-49, pp 39-46

Matney TG, Belli KL, Farrar RM, Jr (1990) Parameter-free diameter-distribution recovery. In: Division 4 Proceedings of the IUFRO World Congress Meeting, Montréal, Que., Canada, 5-11 August 1990. Publ. FWS-2-90. School of Forestry and Wildlife Resources, Virginia Polytechnic Institute and State University, Blacksburg, Va, pp 95-107

McTague JP, Stansfield WF (1994) Stand and tree dynamics of uneven-aged ponderosa pine. Forest Sci 40:289-302

McTague JP, Stansfield WF (1995) Stand, species, and tree dynamics of an uneven-aged, mixed conifer forest type. Can J Forest Res 25:803-812

Moore JA, Zhang L, Newberry JD (1994) Effects of intermediate silvicultural treatments on the distribution of within-stand growth. Can J Forest Res 24:398-404

Munro DD (1974) Forest growth models - a prognosis. In: Fries J (ed) Growth Models for Tree and Stand Simulation, Res. Note 30. Royal College of Forestry, Stockholm, pp 7-21

Nepal SK, Somers GL (1992) A generalized approach to stand table projection. Forest Sci 38:120-133

Newbold P, Granger CWJ (1974) Experience with forecasting univariate time series and the combination of forecasts. J R Stat Soc Ser A 137:131-165

Pienaar LV, Harrison WM (1988) A stand table projection approach to yield prediction in unthinned even-aged stands. Forest Sci 34:804-808

Qin J, Cao QV (2006) Using disaggregation to link individual-tree and whole-stand growth models. Can J Forest Res 36:953-960

Ritchie MW, Hann DW (1997) Implications of disaggregation in forest growth and yield modeling. Forest Sci 43:223-233

Tang X (1992) Forecasting Theory with its Applications (in Chinese with English abstract). University of Electronic Science and Technology of China, Chengdu, China. 288

Tang X (1994) Some new results of the efficient frontier of portfolio investment J UEST China 23:301-305

Wells OO, Wakeley PC (1966) Geographic variation in survival, growth, and fusiform rust infection of planted loblolly pine. Forest Sci Monogr 11:40

Yue CF, Kohnle U, Hein S (2008) Combining tree- and stand-level models: a new approach to growth prediction. Forest Sci 54:553-566

Zhang L, Moore JA, Newberry JD (1993) Disaggregating stand volume growth to individual trees. Forest Sci 39:295-308

Zhang S, Amateis RL, Burkhart HE (1997) Constraining individual tree diameter increment and survival models for loblolly pine plantations. Forest Sci 43:414-423

Zhang X, Lei Y, Cao QV (2010) Compatibility of stand basal area predictions based on forecast combination. Forest Sci 56:552-557

\section{doi:10.1186/s40663-014-0018-z}

Cite this article as: Cao: Linking individual-tree and whole-stand models

for forest growth and yield prediction. Forest Ecosystems 2014 1:18.

\section{Submit your manuscript to a SpringerOpen ${ }^{\circ}$ journal and benefit from:}

- Convenient online submission

- Rigorous peer review

- Immediate publication on acceptance

- Open access: articles freely available online

- High visibility within the field

- Retaining the copyright to your article

Submit your next manuscript at $>$ springeropen.com 